\title{
The Survey of Recognition about Rehabilitative Robots for Treatmentin Physical Therapists
}

\author{
Hyosuk Kim², Dong Jin Kang², Deok Hyen Kim², Seo Jeong Park², Seong Yong Lee², Jeong Min Lee², Seung Yeon Jo², \\ Bo Ram Choi ${ }^{2}$, Minhee Kim² \\ 'Department of Physical Therapy, Graduate School of Health Science, Eulji University, Daejeon, Republic of Korea; ${ }^{2}$ Department of Physical Therapy, \\ College of Health Science, Eulji University, Seongnam, Republic of Korea
}

Purpose: This study examined the recognition of rehabilitative robots for treatment in physical therapists.

Methods: This study surveyed 100 physical therapists in Seoul and Gyeonggi-do using Google Form, an online survey tool. The questionnaire consisted of 21 questions, including eight questions on the general characteristics, 13 questions on the recognition of rehabilitative robots.

Results: The general characteristics of the physical therapists showed differences and influences on recognition of rehabilitative robots, and there were statistically significant differences. There were significant differences in the recognition of rehabilitation robots according to general characteristics in gender, age, education degree, type of hospital, average weekly working time, and treatment field. Multiple regression analysis found that gender and the type of hospital influenced the recognition of rehabilitation robots.

Conclusion: Physical therapists showed differences in recognition of rehabilitative robots according to their general characteristics, and gender and the type of hospital influence the recognition of rehabilitation robots. Sufficient systematic education programs should be provided, and physical therapists require policy adjustments to increase their accessibility to rehabilitation robots through continuing education.

Keywords: Physical therapy, Rehabilitative robots, Recognition about rehabilitative robots

서 론

최근 4 차 산업혁명을 통해 의료분야에서 획기적인 발전을 이뤄내고 있는데, 특히 로봇, 인공지능, 빅데이터, 3D 프린팅, 정밀 의료 등 다양 한 영역이 관심과 주목을 받고 있다. 재활 의료 분야에서는 재활 로 봇영역이 급속도로 성장하고 있고, 임상 및 일상생활에서 다양한 환 자와 보호자들을 위해 다양한 방식으로 적용되고 있다. 노령인구가 급격히 증가함에 따라 노령인구에서 주로 발생하는 퇴행성 질환 및 뇌졸중 발병률이 크게 증가하고, 이와 관련하여 재활 로봇에 대한수 요는 계속 증가할 것으로 예측된다. ${ }^{2}$

재활 로봇 기반의 재활은 일관적인 훈련 및 치료를 가능하게 하고 입력된 데이터로부터 사용자의 수행능력에 대한 정보를 피드백하여 유연하고 적절한 움직임과 강도를 제공할 수 있는 장점이 있다. ${ }^{3}$ 또한 재활 로봇은 주로 뇌졸중과 척수손상 같은 상위 신경 운동원 및 중 추신경계 손상 환자에서 훈련을 목적으로 사용되는데, 가변적이고
다양하며 조절된 움직임의 제공을 통해 신경 가소성에 영향을 주어 운동 및 기능 회복의 가능성을 시사하는 연구 보고가 있었다.4-6 이러 한 재활 로봇의 사용은 해외뿐만 아니라 국내에서도 수요가 점차 높 아지는 추세이며, 신체적 기능 회복을 돕는 재활 로봇 뿐만 아니라 인 지, 심리, 발달과 같은 다양한 임상 분야에서도 재활 로봇이 적용되고 있다. 그러나 재활 로봇을 활용한 치료에서 기저질환이 있는 환자나 노인의 경우 골다공증에 의한 골절, 심장마비 등의 위험 요소가 존재 하므로 각별한 주의가 필요하고, 착용형 로봇의 경우에는 환자가 로 봇에 구속되어 있어 낙상 시 더 큰 충격을 받을 가능성이 존재하기 때문에 활용의 각별한 주의가 필요하다.,4

최근 다양한 재활 로봇은 재활 과정에서 과도하게 소모되는 물리 치료사들의 노동력 및 비용 측면에서의 절감을 위한 대안으로 주목 받고 있다. 재활 로봇을 이용하면 한 명의 물리치료사가 여러 환자를 동시에 훈련할 수 있어, 물리치료사의 신체 노동을 줄이고 일관성 있 는 치료를 제공할 수 있다. ${ }^{89}$ 치료 기간을 단축하여 개인적인 비용의 
절감도 기대할 수 있다. ${ }^{10}$ 또한 보행 훈련에서 체중 지지가 가능하도 록 설계되어 보다 안전하게 치료를 시행할 수 있다." 이러한 재활 로 봇의 필요성과 요구도의 증가에도 불구하고 현재까지 국내 재활 로 봇과 관련된 인식에 대한 연구가 부족하며, 특히 국내의 물리치료사 를 대상으로 재활 로봇에 대한 전반적인 재활 로봇 인식도를 조사한 연구 또한 매우 부족한 실정이다.5 이에 본 연구는 임상 물리치료사의 치료용 재활 로봇에 대한 인식도를 조사하여 재활 로봇 인식도에 대 한 현황 및 흐름을 파악하고 조사하고자 한다.

\section{연구 방법}

\section{1. 연구 대상}

본 연구는 서울, 경기 지역 소재의 병원에서 근무하는 물리치료사 100 명을 대상으로 실시하였다. 본 연구를 진행하기 위해 2020년 9월 10 일부터 22 일까지 13 일간 구글에서 제공하는 온라인 설문지 서비스 인 구글 설문지(Google Forms, Google Inc., CA, USA)를 이용하여 설 문조사를 실시하였으며, 자기 기입방식을 사용하였다. 설문을 시작 하기에 앞서 연구 대상자들에게 연구의 목적에 관해 설명하고, 이를 충분히 숙지한 후 설문에 참여할 수 있도록 하였다. 배포된 설문 중 응답이 온 103 부에서 설문의 불성실로 탈락된 3 부를 제외한 총 100 부의 설문지를 연구에 활용하였다.

\section{2. 측정도구 및 방법}

본 연구에서 사용한 설문지는 물리치료사의 재활 로봇에 대한 인식을 조사하기 위하여, 일반적인 특성 8 문항, 재활 로봇에 대한 인식 13 문항 등총 21 문항으로 구성되었다. 각 문항에 따른 도구는 아래와같다.

\section{1) 일반적 특성}

일반적 특성은 $\operatorname{Park}^{12}$ 의 연구에서 제시된 문항 중 성별, 연령, 최종학 력 등 총 8 개의 문항을 수정하고, Jung ${ }^{13}$ 과 $\mathrm{Ko}^{14}$ 의 연구에서 활용한 문 항 일부를 추가하여 구성하였다.

\section{2) 재활 로봇에 대한 인식의 측정}

재활 로봇에 대한 인식을 측정하기 위하여 선행연구에서 제시된 문 항을 수정하여 총 13 문항의 설문을 구성하였다. ${ }^{15}$ 재활 로봇의 존재 인식, 재활 로봇을 알게 된 경로, 재활 로봇의 사용 또는 관찰 경험, 알 고 있는 재활 로봇의 분야, 재활 로봇과 물리치료 업무와의 관련성, 국내 재활 로봇프로그램의 체계성, 재활 로봇 치료 프로그램의 필요 성, 필요하거나 필요하지 않은 이유, 재활 로봇 서비스 제공 시 문제점, 인식 개선을 위해 필요한 점, 재활 로봇 관련 교육에 참여할 의향, 물 리치료에서 재활 로봇 맞춤 서비스의 필요성 등에 대한 질문을 포함
하고 있다. 그중 재활 로봇 인식에 대한 질문의 답변은 리커트 척도로 점수가 높을수록 재활 로봇에 대한 인식이 긍정적인 것을 의미한다.

\section{3. 자료분석}

본 연구분석을 위하여 수집된 자료는 통계 프로그램인 SPSS (Statistical Package for Social Science for Window, IBM Inc. Armonk, NY) Ver$\operatorname{sion} 22.0$ 을 사용하였다. 일반적 특성과 재활 로봇에 대한 인식을 조 사하기 위해, 빈도 분석과 기술 통계량 분석을 수행하였다. 일반적인 특성에 따른 재활 로봇 인식도의 차이의 유의성을 파악하기 위하여 paired t-test와 일원 배치 분산분석(one-way ANOVA)을 실시하였으며, 유의한 항목에 대한 사후분석은 Scheffe test를 실시하였다. 또한 일반 적 특성이 재활 로봇의 인식도에 미치는 영향을 알아보기 위해 다중 회기분석(multiple regression analysis)을 실시하였다. 통계학적 유의수 준은 0.05 로 설정하였다.

\section{결 과}

\section{1. 일반적 특성}

본 연구에서 조사대상자의 일반적 특성을 알아보기 위해 물리치료사 집단에 대해 빈도분석을 실시하였다. 물리치료사의 일반적 특성을 보 면 성별, 연령, 근무 년 수, 최종학력, 월 평균수입, 근무 기관, 주당 근무 시간, 주요 치료 분야를 조사하였으며, 그 결과는 다음과 같다(Table 1). 성별은 여성이 58명으로 남성 42명보다 많았고, 연령은 20-24세 17 명, 25-29세 44명, 30-39세 32명, 40-49세 4명, 50세 이상 3명으로, 근무 년 수는 1년 미만 26명, 1-4년 미만 31명, 4-7년 미만 13명, 7년 이상 30명 으로 나타났다. 최종학력은 전문학사 9 명, 학사 81 명, 석사 8 명, 박사 2 명으로, 월 평균 수입은 100-200만 원 23명, 200-300만 원 46명, 300-400 만 원 21 명, 400 만 원 이상 10 명으로 나타났다. 근무 기관은 대학. 종합 병원 35 명, 병원 13 명, 재활병원 13 명, 요양병원 6 명, 의원 30 명, 기타 3 명 으로, 주당 근무시간은 20시간 이하 1명, 21-30시간 2명, 31-40시간 51 명, 41 시간 이상 46 명으로, 주요 치료 분야에서는 근골격계 54 명, 신경 계 39 명, 소아 6 명, 스포츠 1명으로 나타났다.

\section{2. 물리치료사의 재활 로봇 인식}

\section{1) 재활 로봇 인식}

물리치료사와 재활 로봇 인식의 정도를 파악하기 위해 평균과 표준 편차를 산출하였으며 그 결과는 다음과 같다(Table 2). 물리치료사의 재활 로봇 인식 전체 평균은 5 점 만점 중 2.87 점으로 나타났다. 재활 로봇 인식도 하위 항목에서는 재활 로봇과 물리치료 업무의 관련성 평균이 3.44 , 재활 로봇에 의한 치료 프로그램 필요성 평균이 3.24 , 물 리치료에서 재활 로봇 맞춤형 서비스의 필요성 평균이 3.15 , 재활 로봇 
Table 1. General Characteristics of physical therapists

\begin{tabular}{|c|c|c|}
\hline Items & $\mathrm{N}$ & $\%$ \\
\hline \multicolumn{3}{|l|}{ Gender } \\
\hline Male & 42 & 42 \\
\hline Female & 58 & 58 \\
\hline \multicolumn{3}{|l|}{ Age } \\
\hline $20-24$ & 17 & 17 \\
\hline $25-29$ & 44 & 44 \\
\hline $30-39$ & 32 & 32 \\
\hline $40-49$ & 4 & 4 \\
\hline Over 50 & 3 & 3 \\
\hline \multicolumn{3}{|l|}{ Clinical career (yr) } \\
\hline Less 1 & 26 & 26 \\
\hline $1-3$ & 31 & 31 \\
\hline $4-6$ & 13 & 13 \\
\hline Over 7 & 30 & 30 \\
\hline \multicolumn{3}{|l|}{ Education degree } \\
\hline Associate degree & 9 & 9 \\
\hline Bachelor's degree & 81 & 81 \\
\hline Master's degree & 8 & 8 \\
\hline Doctorate degree & 2 & 2 \\
\hline \multicolumn{3}{|c|}{ Average monthly income (won) } \\
\hline 1-2 million & 23 & 23 \\
\hline 2-3 million & 46 & 46 \\
\hline 3-4 million & 21 & 21 \\
\hline Over 4 million & 10 & 10 \\
\hline \multicolumn{3}{|l|}{ Type of hospital } \\
\hline University & 35 & 35 \\
\hline \multicolumn{3}{|l|}{ General hospital } \\
\hline hospital & 13 & 13 \\
\hline Rehabilitation hospital & 13 & 13 \\
\hline Geriatric hospital & 6 & 6 \\
\hline Clinic & 30 & 30 \\
\hline Others & 3 & 3 \\
\hline \multicolumn{3}{|c|}{ Average weekly working time (hr) } \\
\hline Less 20 & 1 & 1 \\
\hline $21-30$ & 2 & 2 \\
\hline $31-40$ & 51 & 51 \\
\hline Over 41 & 46 & 46 \\
\hline \multicolumn{3}{|l|}{ Main treatment field } \\
\hline Musculoskeletal & 54 & 54 \\
\hline Nervous & 39 & 39 \\
\hline Pediatric & 6 & 6 \\
\hline Sports & 1 & 1 \\
\hline
\end{tabular}

관련 교육에 참여할 의향 평균이 2.86 , 재활 로봇 존재인식 평균이 2.30 , 재활로봇프로그램의 체계적인 실시 평균이 2.23 순으로 나타났다.

\section{2) 재활 로봇 인식 관련 하위 요인}

재활 로봇 인식 관련 하위 요인을 파악하기 위해 확인 경로, 사용 및
Table 2. Recognition of rehabilitative robot of physical therapists

\begin{tabular}{lc}
\hline Items & Physical Therapist \\
\hline Presence awareness & $2.30 \pm 0.59$ \\
Relevance to physical therapy work & $3.44 \pm 0.55$ \\
Korea's systematicity & $2.23 \pm 0.73$ \\
Necessity & $3.24 \pm 0.63$ \\
Willingness to participate in education & $2.86 \pm 0.76$ \\
Necessity of customized service for rehabilitative robots & $3.15 \pm 0.63$ \\
Total & $2.87 \pm 0.80$
\end{tabular}

Mean \pm SD.

관찰 경험 여부, 알고 있는 분야, 재활 로봇이 필요한 이유, 필요하지 않은 이유, 서비스 제공 시 예상되는 문제점, 인식개선을 위해 필요한 사항을 조사하였고, 그 결과는 다음과 같다(Table 3).

재활 로봇에 대해 알게 된 경로에 대한 응답에서 인터넷은 15 명, 외 부교육은 10 명, 박람회는 8 명. 그리고 근무처에서의 사용은 46 명이며, 학과 전공수업은 9 명이고, 기타는 12 명으로 물리치료사는 근무처에 서의 사용으로 재활 로봇을 많이 알게 되는 것으로 나타났다. 사용 및 관찰 경험에서 응답한 물리치료사의 47 명 $(54.00 \%)$ 이 사용 및 관찰 경험이 있으며, 물리치료사 40 명 $(46.00 \%)$ 이 사용 및 관찰 경험이 없는 것으로 나타났다. 알고 있는 재활 로봇 분야를 질문하는 문항에서 보 행이나 손 기능 훈련 등의 운동 재활 분야에 대해 알고 있는 물리치료 사는 80 명 $(54.80 \%)$, 식사 보조 등의 일상생활 보조 분야는 21 명 $(14.40 \%)$, 인지 재활 분야는 15 명(10.30\%), 로봇 슈트 분야는 30 명(20.50\%)으로 나타났다.

재활 로봇이 필요하다고 응답한 물리치료사는 80 명이었고, 필요하 지 않다고 한 인원은 20 명이었다. 재활 로봇이 필요하다고 응답한 사 람 중에서 재활 로봇이 필요한 이유에 대해 62 명 $(77.50 \%)$ 이 대부분의 환자에게 적절하고 질 높은 중재를 제공하기 위해서라고 응답했으 며, 11 명 $(13.75 \%)$ 이 물리치료사의 영역을 확대하기 위해서, 7 명 $(8.75 \%)$ 이 물리치료사들의 근무 조건을 향상하기 위해서라고 응답하였다. 재활 로봇이 필요하지 않다고 응답한 사람 중 재활 로봇이 필요하지 않은 이유에 대해서는 높은 비용으로 치료에 대한 접근성이 떨어져 서라고 물리치료사의 9 명(45.00\%)이 응답하였고, 11 명(55\%)는 체계적 인 재활 로봇의 프로그램이 개발되지 않아서라고 응답하였다.

재활 로봇 서비스의 문제점에 대한 응답에서 비용에 대한 부담이 크다고 답변한 경우는 55 명이 답하였고, 정보의 부족은 10 명, 적절한 재활 로봇기기의 부재는 34 명, 고용주의 무관심은 1 명이 응답하였다.

인식개선을 위해 필요한 사항에 대한 응답에서 타 전문 영역과 연 계한 워크숍은 18 명으로 나타났고, 협회 보수교육은 6 명, 전문 자격 증 제도의 도입 방안은 18 명, 재활 로봇 관련 전공개설은 16 명, 제도적 지원은 42 명이 응답하였다. 
Table 3. Sub-factors related to recognition of rehabilitative robot

\begin{tabular}{|c|c|c|}
\hline Items & $\mathrm{N}$ & $\%$ \\
\hline \multicolumn{3}{|l|}{ Known Route } \\
\hline Internet & 15 & 15.00 \\
\hline External education & 10 & 10.00 \\
\hline Exhibition & 8 & 8.00 \\
\hline Work place & 46 & 46.00 \\
\hline Major class & 9 & 9.0 \\
\hline Others & 12 & 12.0 \\
\hline \multicolumn{3}{|c|}{ Experience of use Rehabilitative Robot } \\
\hline Yes & 47 & 54.0 \\
\hline No & 40 & 46.0 \\
\hline \multicolumn{3}{|c|}{ Awareness of the field (multiple responses) } \\
\hline Exercise rehabilitation & 80 & 54.80 \\
\hline Activities of daily living & 21 & 14.40 \\
\hline Cognitive rehabilitation & 15 & 10.30 \\
\hline Robot suit & 30 & 20.50 \\
\hline Others & 0 & 0 \\
\hline \multicolumn{3}{|l|}{ Reason of Necessity } \\
\hline High quality intervention & 62 & 77.50 \\
\hline Variety of areas & 11 & 13.75 \\
\hline Improve working conditions & 7 & 8.75 \\
\hline \multicolumn{3}{|l|}{ Reason of Unnecessity } \\
\hline High cost & 9 & 45.00 \\
\hline Unstructured program & 11 & 55.00 \\
\hline Reducing work place & 0 & 0 \\
\hline \multicolumn{3}{|l|}{ Problems with Service Provision } \\
\hline High cost & 55 & 55.00 \\
\hline Lack of information & 10 & 10.00 \\
\hline Absence of a suitable & 34 & 34.00 \\
\hline \multicolumn{3}{|l|}{ rehabilitative robot } \\
\hline Employer's indifference & 1 & 1.00 \\
\hline \multicolumn{3}{|c|}{ What is Needed to Improve Awareness } \\
\hline Work Shop & 18 & 18.00 \\
\hline Refresher training & 6 & 6.00 \\
\hline The introduction of a certificate & 18 & 18.00 \\
\hline Opening of one's major & 16 & 16.00 \\
\hline Legal supplement & 42 & 42.00 \\
\hline
\end{tabular}

3) 물리치료사의 일반적인 특성에 따른 재활 로봇 인식도의 차이

재활 로봇의 인식도에서 일반적 특성 중 어떠한 항목에 따라 차이가 있는지에 대하여 분석한 결과, 성별, 연령, 학력, 근무기관, 근무시간, 치료하는 환자군에서 통계적으로 유의한 차이가 나타났다 $(\mathrm{p}<0.05)$ (Table 4). 재활 로봇 인식도는 일반적인 특성 중 성별에서 남성이 여성 보다 인식도가 높았고, 연령에서는 30-39세, 근무 년 수는 4-7년 근무 자의 인식도가 가장 높은 것으로 나타났다. 대상자의 최종학력과 관 련하여 재활 로봇 인식도는 석사와 박사가 학사, 전문학사에 비해 인 식도가 높게 나타났다. 월 평균 소득에서 300-400만 원의 급여를 받 는 물리치료사가 인식도가 가장 높은 것으로 나타났다. 근무하고 있
는 기관의 종별에서 대학. 종합병원에서 근무하는 물리치료사는 타 기관에 종사하는 물리치료사보다 인식도가 유의성 있게 높았고, 근 무시간에서 31-40시간 근무하는 물리치료사가 가장 인식도가 높았 으며, 치료하는 환자군에서 소아 물리치료사의 인식도가 가장 높게 나타났다.

\section{4) 물리치료사의 일반적 특성이 재활 로봇 인식도에 미치는 영향}

물리치료사의 일반적 특성(성별, 연령, 근무 년 수, 최종학력, 월 평균 수입, 근무기관, 주당 근무시간, 치료 환자군)이 재활 로봇 인식도에 미치는 영향을 알아보기 위해 회귀분석을 진행하였다(Table 5). 독립 변수인 물리치료사의 일반적 특성은 종속변수인 재활 로봇 인식도 에 $43.5 \%$ 의 설명력을 가지고 있으며 회귀모형은 통계적으로 유의한 것으로 나타나 회귀모형이 적합하였다 $(\mathrm{p}<0.05)$. 독립변수 중 성별(남 성), 근무기관(대학. 종합병원) 이 재활 로봇 인식도에 유의한 영향이 있었는데 $(\mathrm{p}<0.05)$, 성별에서 남성이 여성보다 재활 로봇 인식도가 높 게 나타났으며, 근무기관에서 대학. 종합병원은 기타보다 재활 로봇 인식도가 높게 나타났다.

\section{고 찰}

산업이 급속도로 발전함에 따라 의료분야에서도 활발한 진보는 계 속 이루어지고 있다. 특히 재활 의료분야에서는 재활 로봇을 이용한 의료 서비스 제공이 증가하는 수요와 함께 지속적인 발전을 하고 있 으며 앞으로도 많은 성장이 예상되고 있다.16 이에 본 연구에서는 치 료용 재활 로봇에 대한 인식도를 확인하고 물리치료사들의 일반적 인 특성이 인식도에 미치는 영향을 확인하여, 물리치료사들이 향후 현장에서 효과적인 재활 로봇 관리와 재활 로봇 인식도 향상 방안 마 련에 기초자료를 제공하고자 한다.

임상에서 근무하고 있는 물리치료사의 재활 로봇 인식 정도에 대 해 조사한 결과, 전반적으로 재활 로봇이 필요하다고 응답하였다. 세 부적으로는 대부분이 재활 로봇 존재에 대해 알고 있다는 것과 임상 업무와의 관련성이 있다고 응답하였고, 재활 로봇은 필요한 것이며 교육 참여에 대해 의향이 있다고 응답하였다. 이러한 결과는 작업치 료사를 대상으로 진행한 선행 연구의 결과와 비슷한 경향을 나타냈 는데, ${ }^{13}$ 이는 대부분의 물리치료사들은 재활 로봇에 대해 알고 있거 나 임상에서의 필요성을 긍정적으로 인지하고 있지만, 임상 현장에 서의 관련 교육이 충분하게 이루어지지 않고 있기 때문에 재활 로봇 에 대해 깊이 있는 이해도가 크게 높지는 않으며, 이를 개선하기 위해 서 재활 로봇에 대한 체계적인 교육 및 세미나 제공이 필요하다고 생 각된다.

재활 로봇 인식도의 하위요인에 대해 조사한 결과에서는 대부분 
Table 4. Differences in recognition of rehabilitation robots according to general characteristics

\begin{tabular}{|c|c|c|c|c|}
\hline \multirow{2}{*}{ Characteristic } & \multirow{2}{*}{ Sortation } & \multicolumn{2}{|c|}{ recognition of rehabilitation robots } & \multirow{2}{*}{ Scheffe } \\
\hline & & $M \pm S . D$ & tor $F / p$ & \\
\hline \multirow[t]{2}{*}{ Gender } & Male & $15.79 \pm 2.24$ & $2.986 / 0.004$ & \\
\hline & Female & $14.41 \pm 2.34$ & & \\
\hline \multirow[t]{5}{*}{ Age } & $20-24$ & $13.70 \pm 2.51$ & $4.932 / 0.001$ & \\
\hline & $25-29$ & $14.73 \pm 2.11$ & & \\
\hline & 30-39 & $16.20 \pm 2.02$ & & \\
\hline & $40-49$ & $14.75 \pm 2.50$ & & \\
\hline & Over 50 & $12.66 \pm 4.04$ & & \\
\hline Clinical & Less 1 & $14.34 \pm 2.56$ & $2.302 / 0.082$ & \\
\hline \multirow[t]{3}{*}{ career (yr) } & $1-3$ & $14.54 \pm 2.14$ & & \\
\hline & $4-6$ & $15.86 \pm 2.03$ & & \\
\hline & Over 7 & $15.54 \pm 2.48$ & & \\
\hline Education & Associate degree & $13.11 \pm 2.20$ & $4.987 / 0.003$ & \\
\hline \multirow[t]{3}{*}{ degree } & Bachelor's degree & $14.92 \pm 2.25$ & & \\
\hline & Master's degree & $17.00 \pm 2.34$ & & \\
\hline & Doctorate degree & $17.00 \pm 2.82$ & & \\
\hline \multirow[t]{4}{*}{ Average monthly income (won) } & $1-2$ million & $15.34 \pm 1.94$ & $2.618 / 0.055$ & \\
\hline & 2-3 million & $14.31 \pm 2.32$ & & \\
\hline & 3-4 million & $15.86 \pm 2.80$ & & \\
\hline & Over 4 million & $15.30 \pm 2.00$ & & \\
\hline \multirow[t]{6}{*}{ Type of hospital } & University General hospital (a) & $16.64 \pm 1.85$ & $9.225 /<0.001$ & a $>$ e \\
\hline & Hospital (b) & $14.92 \pm 1.89$ & & \\
\hline & Rehabilitation hospital (c) & $13.92 \pm 2.25$ & & \\
\hline & Geriatric hospital (d) & $15.33 \pm 2.16$ & & \\
\hline & Clinic (e) & $13.50 \pm 2.22$ & & \\
\hline & Others ( $f$ ) & $14.00 \pm 0.00$ & & \\
\hline \multirow[t]{4}{*}{ Average weekly working time (hr) } & Less 20 & 11 & $3.848 / 0.012$ & \\
\hline & $21-30$ & $15.00 \pm 1.41$ & & \\
\hline & $31-40$ & $15.67 \pm 2.33$ & & \\
\hline & Over 41 & $14.33 \pm 2.27$ & & \\
\hline \multirow[t]{4}{*}{ Main treatment field } & Musculoskeletal & $14.23 \pm 2.27$ & $4.720 / 0.004$ & \\
\hline & Nervous & $15.80 \pm 2.36$ & & \\
\hline & Pediatric & $16.42 \pm 1.39$ & & \\
\hline & Sports & 14 & & \\
\hline
\end{tabular}

의 응답자들이 환자에게 적절하고 질 높은 중재를 제공하기 위해 재 활 로봇이 필요하다고 답하였지만 임상에서 사용하거나 사용 경험 이 있다고 대답한 비율은 약 절반 정도 수준에 그쳤으며, 재활 로봇 은 필요한 중재이지만 물리치료사의 인식도 개선을 위한 제도적 지 원이 필요하다고 응답하였다. 최근 재활 로봇에 대해 점점 증가하는 수요에 맞춰 국내의 재활 로봇 개발 연구에 대한 적극적인 지원과 재 활 로봇 시스템을 다양한 의료기관에 보급하는 노력이 필요하다. 또 한 향후 재활 로봇의 발전과 인식 향상을 위해 저렴하면서 양질인 로 봇의 보급에 힘쓰며, 체계적인 프로그램을 개발, 공적 급여, 건강보험 의 지원이 필요하다. 뿐만 아니라, 물리치료사들 및 임상인들에 대한 체계적인 교육 시스템을 마련하는 등 정부와 공공기관이 주도적으
로 제도적 및 재정적 지원의 제공이 필요하다.17

물리치료사의 일반적인 특성에 따른 재활 로봇 인식도의 차이를 분석한 결과 성별, 연령, 학력, 근무 기관, 근무 시간, 치료하는 환자군 요소에서 각각 통계적으로 유의한 차이를 나타냈다. 먼저 성별에서 는 남성이 여성보다 인식도가 유의하게 높았다. 물리치료사의 일반적 인 특성이 재활 로봇 인식도에 미치는 영향을 분석한 회귀분석 결과 에서 또한 성별에서 유의한 결과값이 나타났다. 10 대 청소년들을 대 상으로 로봇 및 프로그래밍에 대해 조사한 선행 연구에서 여성보다 남성에서 로봇 프로그램에 대한 더 큰 자신감을 가지고 있는 것으로 나타났다. ${ }^{18}$ 또한 20 대 일반인들을 대상으로 의료용 수술 로봇 및 새 로운 기술 인식도에 대한 연구에서는 두 성별 모두 전반적인 인식도 
Table 5. Influence of general characteristics on recognition of rehabilitation robots

\begin{tabular}{|c|c|c|c|c|c|c|}
\hline \multirow{2}{*}{ Characteristic } & \multicolumn{2}{|c|}{ Unstandardized Coefficients } & \multirow{2}{*}{$\frac{\text { Standardized Coefficients }}{\beta}$} & \multirow{2}{*}{$\mathrm{t}$} & \multirow{2}{*}{$\mathrm{p}$} & \multirow{2}{*}{ Remark } \\
\hline & $B$ & Standard error & & & & \\
\hline Gender & 0.877 & 0.436 & 0.182 & 2.008 & 0.048 & $R=0.660$ \\
\hline Age & -0.458 & 0.386 & -0.173 & -1.189 & 0.238 & $R^{2}=0.435$ \\
\hline Clinical career (yr) & 0.171 & 0.326 & 0.084 & 0.524 & 0.601 & $F=4.842$ \\
\hline Education degree & 0.759 & 0.471 & 0.160 & 1.613 & 0.110 & $p<0.001$ \\
\hline Average monthly income (won) & 0.223 & 0.343 & 0.084 & 0.651 & 0.517 & \\
\hline \multicolumn{7}{|l|}{ Type of hospital } \\
\hline University General hospital & 2.581 & 1.263 & 0.520 & 2.043 & 0.044 & \\
\hline Hospital & 1.731 & 1.335 & 0.242 & 1.297 & 0.198 & \\
\hline Rehabilitation hospital & -0.01 & 1.490 & -0.001 & -0.007 & 0.995 & \\
\hline Geriatric hospital & 1.079 & 1.524 & 0.106 & 0.708 & 0.481 & \\
\hline Clinic & 0.546 & 1.291 & 0.104 & 0.423 & 0.674 & \\
\hline Average weekly working time (hr) & -0.034 & 0.367 & -0.008 & -0.092 & 0.927 & \\
\hline \multicolumn{7}{|l|}{ Main treatment field } \\
\hline Musculoskeletal & -0.513 & 2.299 & -0.108 & -0.223 & 0.824 & \\
\hline Nervous & 0.773 & 2.387 & 0.158 & 0.324 & 0.747 & \\
\hline Pediatric & 1.226 & 2.458 & 0.130 & 0.499 & 0.619 & \\
\hline
\end{tabular}

나 이해도는 낮았지만, 여성에서 수술 로봇에 대한 두려움과 낮은 신 뢰도를 가진 것으로 나타났다. ${ }^{19}$ 이러한 선행 연구의 결과를 통해서 남성에서 로봇에 대한 전반적인 심리상태나 높은 자신감이 남성 물 리치료사의 재활 로봇에 대한 높은 인식도와 연관성이 있을 것으로 생각된다.

연령에서는 30대(30-39세)의 인식도가 가장 높은 것으로 분석되었 으며 대상자의 최종학력에서는 석사 및 박사 학위 대상자에서 인식 도 점수가 높은 것으로 나타나 연령과 학위가 높을수록 재활 로봇 활 용에 대한 인식이 대체로 높은 것으로 분석되었다. 이는 업무와 관련 된 종합적이고 전문적인 이해와 전공 지식이 많아질수록 재활 로봇 에 대한 이해도, 선호도, 그리고 긍정적 인식 등이 함께 심화되는 현 상과 관련된다고 볼 수 있다. ${ }^{20}$

근무 시간과 관련된 결과에서는 주 31-40시간 근무하는 치료사의 인식도가 가장 높게 나타났고, 근무 기관의 결과는 대학. 종합병원에 서 근무하는 대상자들의 인식도가 가장 높게 나타났다. 이는 국내 의 료 재활 로봇 보급사업에 따라 고가의 재활 로봇이 임상연구를 주도 적으로 수행할수 있는 대학 병원과 국립 의료 기관 위주로 보급된 상 황과 관련된다. 또한 심리적으로 긍정적인 상황에서 특정 사안에 대 한 인식도가 높아지는 것과 관련하여, ${ }^{21}$ 재활 로봇에 대한 높은 인식 도는 병원의 근무 시간과 유의한 관계가 있는 것으로 분석된다. 의료 기사를 대상으로 한 직업 만족도 조사에서 평일 및 주간 위주로 업무 를 하는 대학 및 종합병원에 재직하는 물리치료사의 직무 만족도가 가장 높은 것으로 나타났다. ${ }^{21}$ 또한 수도권 물리치료사들의 직무만족 도를 조사한 연구에서 대학 및 종합 병원에서 근무하는 대부분의 물
리치료사는 40 시간 이하로 근무를 하는 것으로 조사되었다. ${ }^{23}$ 근무 하는 의료기관의 종류와 주당 근무 시간이 관계가 있고, 이러한 근무 사항은 재활 로봇 인식도와 관련된다.

대상자의 근무 기관에 따른 결과에서, 소아 및 신경계 분야에서 근 무하는 물리치료사가 재활 로봇에 대한 인식도가 높은 것으로 나타 났다. 이는 근무 기관이나 치료 업무 영역과 관련성이 클수록 연관성 이 있는 분야에 대한 인식도가 높았다고 보고한 Liu 등 24 의 선행 연구 와 관련하여 정보 노출 경험이 본 연구에서도 마찬가지로 대상자의 인식도에 큰 영향을 미친 것으로 생각된다.

또한 작업치료사를 대상으로 재활 로봇 인식도를 조사한 연구 결 과에서 재활 로봇에 관한 대상자들이 교육 참여 기회 확대에 대한 필 요성을 강조한 것과 같이, ${ }^{15}$ 향후 재활 로봇에 대해 인식도 개선을 위 해 학부 교육뿐만 아니라 졸업 후 보수 교육을 통해서 활발하고 지속 적인 교육이 필요하다. 아직 국내에서 재활 로봇 치료에 대한 적정 의 료 수가화가 책정되지 않아 재활 로봇의 다양한 임상 영역으로의 연 계 및 보급에 한계가 있다. ${ }^{17}$ 따라서 대학 및 종합병원급 이외의 다양 한 의료기관에서 로봇 장비의 보편화 및 필요성에 대한 인식 증진을 위해 정부의 제도적 지원, 전문 자격증 과정 신설, 그리고 이와 관련 된 전반적인 법적 제도 마련과 같은 적극적인 개선이 필요하다.

본 연구는 서울 및 경기 지역 소재로 한정하여 진행하였고 40 대 이 상의 대상자가 부족하여 모든 물리치료사에게 일반화시키기에는 제 한이 있다. 따라서 신뢰도 높은 결과를 얻기 위해 추후에는 다양한 연령과 지역의 대상자를 확보한 연구를 제언한다.

본 연구에서 물리치료사들의 일반적 특성에 따른 재활 로봇 인식 
은 성별, 연령, 최종학력, 근무 기관, 주당 근무 시간, 치료 환자군에서 유의한 차이가 있으며, 이중 성별과 근무기관이 재활 로봇 인식에 영 향을 끼치는 것으로 나타났다. 이러한 결과를 바탕으로 재활 로봇을 활용한 치료 경험과 교육을 통한 정보습득의 필요성이 요구되는 것 과 관련하여 재활 로봇 업무와 교육 참여의 의지가 증대될 수 있도록 학부 교육에서부터 재활 로봇에 대한 올바른 인식과 의식의 전환을 위한 체계적인 교육프로그램을 제공해야 하며, 졸업 이후에도 보수 교육과 워크숍 등을 통해 재활 로봇 관련 접근성을 높일 수 있는 정 책적 조정이 필요한 부분이라 생각된다.

\section{REFERENCES}

1. Kim KB, Han KH. A study of the digital healthcare industry in the fourth industrial revolution. JCIT. 2020;10(3):7-15.

2. Krebs HI, Volpe BT. Rehabilitation robotics. Handb Clin Neurol. 2013; 110:283-94.

3. Laut J, Porfiri M, Raghavan P. The present and future of robotic technology in rehabilitation. Curr Phys Med Rehabil Rep. 2016;4(4):312-9.

4. Molteni F, Gasperini G, Cannaviello G et al. Exoskeleton and end-effector robots for upper and lower limbs rehabilitation: narrative review. PM\&R. 2018;10(9):S174-88.

5. Kim JS, Park SW, Lee YS et al. Clinical outcomes of robot-assisted arm rehabilitation in stroke patients. Brain Neurorehabil. 2015;8(1):46-52.

6. Seo HG, Beom JW, Oh BM et al. Effects of robot-assisted upper limb training on hemiplegic patients. Brain Neurorehabil. 2014;7(1):39-47.

7. Song JH, Oh MK, Sim EJ et al. A systematic review on the present condition of the internal robot therapy. JKCBOT. 2016;6(1):49-60.

8. Butler DP, Willett K. Wii-habilitation: Is there a role in trauma? Injury. 2010;41(9):883-5.

9. Jack D, Boian R, Merians AS et al. Virtual reality-enhanced stroke rehabilitation. IEEE Trans Neural Syst Rehabilitation Eng. 2001;9(3):308-18.

10. Hwang SJ, Yoo DH. Effects of robot-assisted therapy on function of upper extremity in stroke patients. JKCBOT. 2013;3(1):34.

11. Park SY. The effects of robot-assisted gait training for the patient with post stroke: a meta-analysis. Phys Ther Korea. 2015;22(2):35.

12. Park JW. Job-stress, self-efficacy and depression of physical and occupational therapists in nursing and rehabilitation hospitals. Kyungpook National University. Dissertation of Master's Degree. 2019.

13. Jung AS. A study on the relations between a health promoting behaviors and self-efficacy in general hospital nurse. Hanyang University. Dissertation of Master's Degree. 2007.

14. Ko HJ. Perception and environmental support related to implementing evidence-based practice (EBP) among occupational and physical therapists. Dongsin University. Dissertation of Master's Degree. 2014.

15. Seo SY, Kim SE. A survey of occupational therapists' recognition about rehabilitation robots. KAFA 2019;11(1):25-8.

16. Gassert R, Dietz V. Rehabilitation robots for the treatment of sensorimotor deficits: a neurophysiological perspective. J Neuroeng Rehabil. 2018; 15(1):46.

17. Song WK. Trends in rehabilitation robots and their translational research in national rehabilitation center, Korea. Biomed Eng Lett. 2016; 6(1):1-9.

18. Nourbakhsh I.R, Hamner E, Crowley K et al. Formal measures of learning in a secondary school mobile robotics course. IEEE Int Conf Robot Autom. 2004;2:1831-6.

19. McDermott H, Choudhury N, Lewin-Runacres M et al. Gender differences in understanding and acceptance of robot-assisted surgery. J Robot Surg. 2020;14(1):227-32.

20. Lee SM. A survey on university students perception of rehabilitation robots: subjects to the department of occupational therapy. KAFA. 2020; 12(1):39-40.

21. Lee KH. A study on the perception of new health technology, self-efficacy and professional self-concept among operating room nurses. Yonsei University. Dissertation of Master's Degree. 2009.

22. Lee EM, Ahn SM. Comparison of factors affecting job stress and satisfaction of medical technician: focus on Incheon area. J Radiol Sci Technol. 2018;41(6):627-35.

23. Shim JH, Yoon TH. Analysis of factors that Influence the job satisfaction of physical therapists. J Kor Soc Phys Ther. 2011;23(1):67-75.

24. Liu D, Cheng G, An AL et al. Public knowledge about dementia in china: a national wechat-based survey. Int J Environ Res Public Health. 2019;16 (21):4231. 